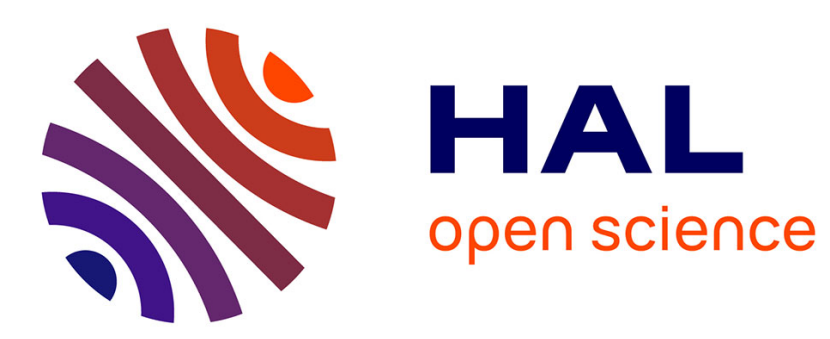

\title{
Organic microcomposites via reactive processing
}

R. Mülhaupt, J. Rösch, S. Demharter

\section{To cite this version:}

R. Mülhaupt, J. Rösch, S. Demharter. Organic microcomposites via reactive processing. Journal de Physique IV Proceedings, 1993, 03 (C7), pp.C7-1519-C7-1524. 10.1051/jp4:19937237 . jpa-00251874

\section{HAL Id: jpa-00251874 https://hal.science/jpa-00251874}

Submitted on 1 Jan 1993

HAL is a multi-disciplinary open access archive for the deposit and dissemination of scientific research documents, whether they are published or not. The documents may come from teaching and research institutions in France or abroad, or from public or private research centers.
L'archive ouverte pluridisciplinaire HAL, est destinée au dépôt et à la diffusion de documents scientifiques de niveau recherche, publiés ou non, émanant des établissements d'enseignement et de recherche français ou étrangers, des laboratoires publics ou privés. 


\title{
Organic microcomposites via reactive processing
}

\author{
R. MÜLHAUPT, J. RÖSCH and S. DEMHARTER
}

Freiburger Materialforschungszentrum und Institut für Makromolekulare Chemie, Stefan-Meier-Str. 31, 7800 Freiburg i.Br., Germany

\begin{abstract}
The in-situ formation of dispersed polyaramide whiskers during melt processing of polymers represents a new route to thermoplastic and elastomeric organic microcomposites. When $\mathrm{N}$-( $\mathrm{p}$-aminobenzoyl)-caprolactam (PAC) is injected into melts of high molecular weight polyamide-6 or dihydroxy-terminated poly(oxytetramethylene) liquid rubber, stable dispersions of polymeric whiskers are formed. At temperatures around $200^{\circ} \mathrm{C}$ PAC poiymerization takes place exclusively through attack of the PAC amine group at the exocyclic carbonyl group, thus eliminating caprolactam and forming whiskers being composed of highly crystalline poly( $p$-phenylenebenzamide). With increasing polymerization temperature, the elimination reaction is accompanied by the competing attack of the amine group at the endocyclic carbonyl group of the caprolactam ring system. This side-reaction causes ring-opening, thus incorporating 6-aminocaproic structural units into the polyaramide backbone. Moreover, the condensation reaction of PAC and N-acyl-caprolactam-functional whisker surfaces with hydroxy- or amine-endgroups affords steric stabilization of the dispersions and excellent interfacial adhesion of the microcomposites. This covalent bond formation between matrix polymer and dispersed in-situ formed polyaramide whiskers is the key to unusual property synergisms of such organic microcomposites. In most cases, small amounts of PAC as additives during processing are sufficient to improve stiffness and strength without sacrificing toughness. Morphologies, mechanical properties, and the basic structure/property relationships of in-situ formed polyaramide-reinforced polyamide- 6 and of polyurethanes elastomers prepared from novel anisotropic polymer polyol dispersions and disocyanates are reported as a function of the PAC content and polymerization conditions.
\end{abstract}

\section{INTRODUCTION}

The characteristic feature of modern advanced composite materials is the alignment of high modulus/high tenacity fibers in a continuous polymeric matrix. When mechanical stresses are applied to such composite materials, the matrix provides efficient stress transfer between the fibers, provided that the interfacial adhesion between fiber and matrix is adequate (1). According to theoretical predictions by Halpin and Tsai (2), the reinforcement, as expressed by the relative Young's modulus enhancement with respect to the non-modified matrix polymer, depends upon the fiber volume fraction, the modulus ratio of fibers versus polymeric matrix, and the aspect ratio, i.e., the ratio of fiber length to fiber diameter. As a consequence, efficient reinforcement is obtained with extremely high modulus fibers with high aspect ratios. Over the recent years, several research groups have attempted to expand this macroscopic reinforcement concept to the molecular or supramolecular level respectively. Stimulated by Flory's early studies on liquid crystals and blends of 
random coil with rigid rod polymers (3), a wide range of LC polymers containing mesogenic units, specialty block copolymers, and blends of rigid rod polymers have been tailored to prepare molecular composites containing molecular dispersions of rigid rod polymers. As an alternative to molecular composites, microcomposites are prepared by dispersing short fibers or other anisotropic microparticles in thermoplastic polymer matrix.

Since most rod-like polymers are inherently infusable and insoluble in common non-protic solvents, most attempts to prepare molecular composites are based on solution blend technologies. For example, Takayanagi (4) has blended low modulus polyamide-6 or polyamide-6,6 together with high modulus poly(p-phenylene terephthalamide) or poly(p-phenylene benzamide) in sulfuric acid or methane sulfonic acid. This solution blend was coagulated in water, thus yielding dispersed polyaramide microfibrils with an aspect ratio of 15-25 and approximately 10-30 nm diameter. More recently, Ogata et al. (5) have introduced the concept of in-situ solution polycondensation of p-hydroxybenzoic acid using their low temperature polycondensation process in the presence of triphenylphosphine. Here the in-situ formed rigid rod poly(p-hydroxybenzoate) phase separates and forms reinforcing microparticles which are dispersed in a continuous polyarylate phase.

For most melt-processed engineering thermoplastics, such solution technologies are not economically feasible in existing processes. At present most processes utilize short fibers or anisotropic filler particles, while few processes are known for the in-situ preparation of microcomposites in polymer melts. One example are polyazomethines, derived from terephthalaldehyde and diamines, which are formed in caprolactam melts. Then the caprolactam monomer is polymerized anionically to form polyamide- 6 containing dispersed rigid rod polyazomethines (6). Objective of our research has been to explore the possibilities of in-situ formation of dispersed slab- or needle-like rigid polymeric microparticles during melt processing. In such processes dual functional monomers are polymerized in polymer melts, thus in-situ producing microphase-separated rigid rod polymers of the desired particle morphologies. Basic requirement is that this polymerization reaction takes place within a few minutes. This paper describes the status of our new reactive processing technology emphasizing the basic structure/property relationships of microcomposites composed of polyaramide whiskers which are dispersed in polyamide- 6 and elastomeric polyurethanes.

\section{POLYAMIDE MICROCOMPOSITES}

Whisker-forming polymerization processes have been described by Yamashita et al. (7) and Kricheldorf et al. $(8,9)$. In both approaches high-temperature polycondensation reactions are performed in inert reaction media. For example, when activated 4-acetoxybenzoic acid is polymerized in high-boiling hydrocarbons, oligomer's phase separate to form whiskers. Subsequently the oligomers are heated for several hours at temperatures exceeding $300{ }^{\circ} \mathrm{C}$. This solid-phase polycondensation is required to build-up molecular weights of the rigid rod polymers. Most engineering thermoplastics such as polyamides would severely undergo thermal degradation when exposed to such reaction conditions. Therefore other more reactive dual-functional monomers were examined to achieve polyaramide whisker formation in polyamide- 6 melts within a few minutes at temperatures well below $300^{\circ} \mathrm{C}$. In a range of various dual functional monomers such as 4-aminobenzoic esters, 2-(4-hydroxyphenyl)-(1,3-oxazoline) and $\mathrm{N}$-(4-aminobenzoyl)-caprolactam (PAC), which is readily prepared from 4-aminobenzoic acid via the 4-sulfinylamino-benzoic acid chloride intermediate (10), only PAC polycondensation in polyamide- 6 melt affords quantitative conversion and formation of the desired anisotropic particles when polycondensation is carried out in polyamide- 6 melts for the duration of 5 minutes at $240^{\circ} \mathrm{C}$. As apparent from Figure 1, when PAC is injected into the melt, the PAC with $\mathrm{T}_{\mathrm{m}}=153^{\circ} \mathrm{C}$ melts and immediately starts to polymerize as verified by increased torque. Caprolactam is evolved and can be stripped off in vacuum. Morphological studies using transmission electron microscopy on stained PAC-modified polyamide-6 (1) clearly 
reveals the presence of needle-shaped microphases of $100-400 \mathrm{~nm}$ average diameter and an aspect ratio of 5-10. In Figure 2 both Young's modulus and yield stress of polyamide- 6 increase with increasing PAC weight fraction, as expected for anisotropic microparticles with similar aspect ratios. From thermal analysis it is possible to conclude that the PAC conversion is complete and that the resulting reaction product melts well above decomposition temperatue of the matrix.

Figure 1. Reactive processing of PAC in polyamide- 6 meit: Mixing-torque as a function of time.

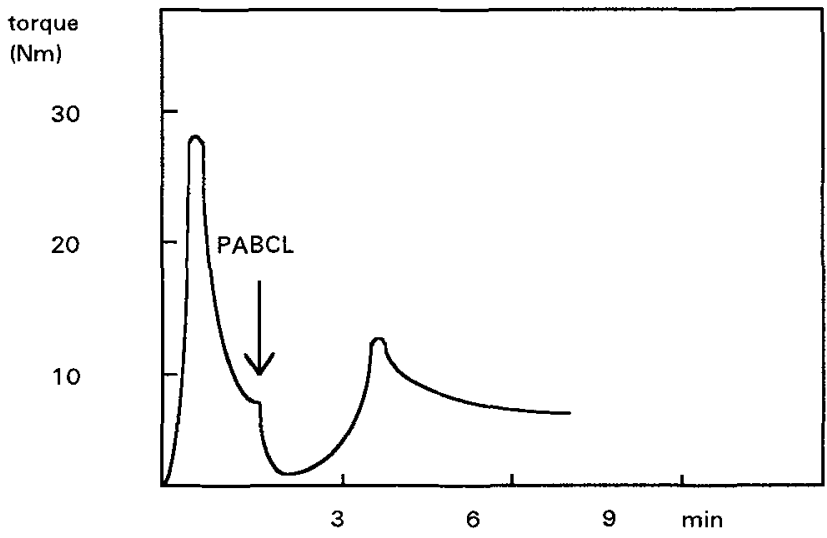

In fact, when particles are isolated by solvent extraction and characterized by X-ray diffraction, it is possible to demonstrate that they are highly crystalline. There is no experimental evidence that such microparticles nucleate the crystallization of the polyamide- 6 matrix.
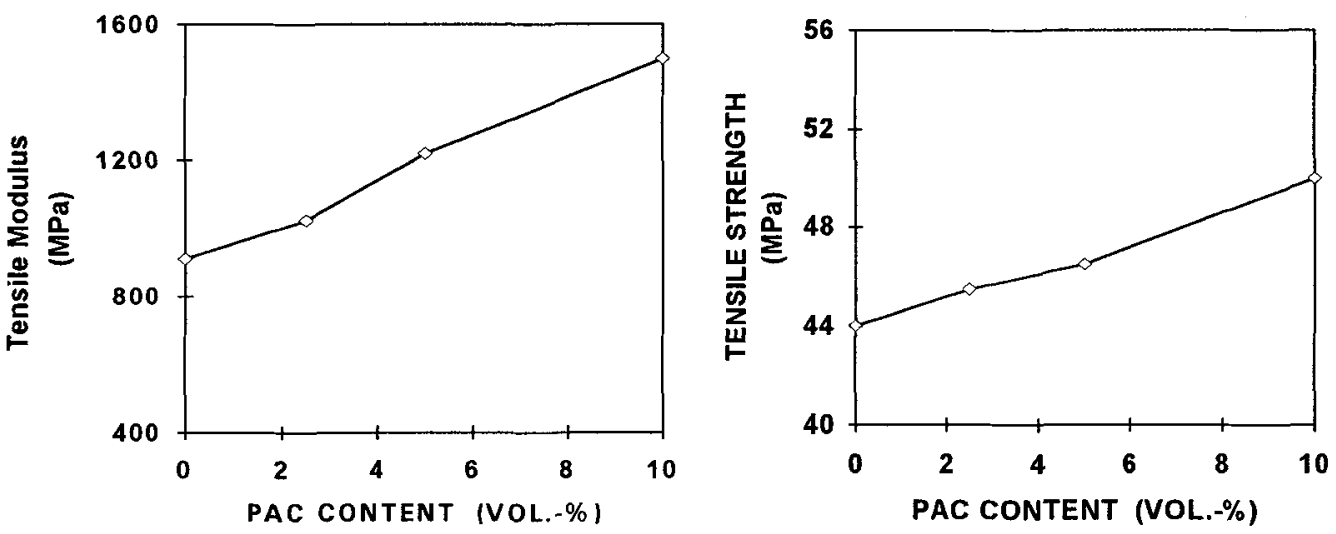

Figure 2. Mechanical properties of polyamide-6/PAC microcomposites: Young's modulus (left) and yield stress (right) as a function of PAC content.

Similar to PAC bulk polymerization (10), there exist two possible reaction pathways for the polycondensation of PAC. When the amine group attacks at the exocyclic carbonyl group of the aminobenzoic acid, caprolactam is eliminated and the desired poly(p-phenylenebenzamide) is formed. As a side reaction, the attack of the amine group can also occur at the endocyclic carbonyl group of the lactam ring system. According to the reaction scheme displayed in Figure 3 , this ringopening reaction yields copolymers of p-aminobenzoic acid with 6-aminocaproic acid. Such copo- 
lymers are considerably less rigid and are not suited as reinforcing anisotropic microphases. The ratio of elimination versus ring-opening reaction depends primarily upon the reaction temperatures. At temperatures around $200^{\circ} \mathrm{C}$, the rigid poly(p-phenylenebenzamide is formed exclusively. As the temperature increases, 6-aminocaproic structural units are incorporated into the polyaramide. Elemental analysis and ${ }^{13} \mathrm{C}$-NMR studies of the microparticles reveal that at $240^{\circ} \mathrm{C}$ the polymer consists of more than $70 \%$ polyaramide with few aminocaproic units incorporated. Assuming that the Young's modulus of the highly crystalline polyaramide microphases are similar to that of corresponding fibers, it is possible to calculate the reinforcement capability of such microfibers. In fact, there exists good agreement between calculated and theoretical values. At 7 vol.- $\%$ whisker content, which corresponds to 10 vol. $\%$ PAC, the Young's modulus modulus increases by $70 \%$ with respect to polyamide- 6 .

In spite of this good agreement between calculated and experimental values, there exists a remarkable difference between fiber-reinforced composites and PAC-based microcomposites. In contrast to high molecular weight high modulus fibers, the whsiker polyaramide are oligomeric with inherent viscosities of $0.1 \mathrm{dl} / \mathrm{g}$. Consistent with PAC bulk polymerization, heating few minutes at $200-240^{\circ} \mathrm{C}$ is not sufficient to effect molecular weight build-up in solid phase polycondensation reactions which require several hours and far higher temperatures.
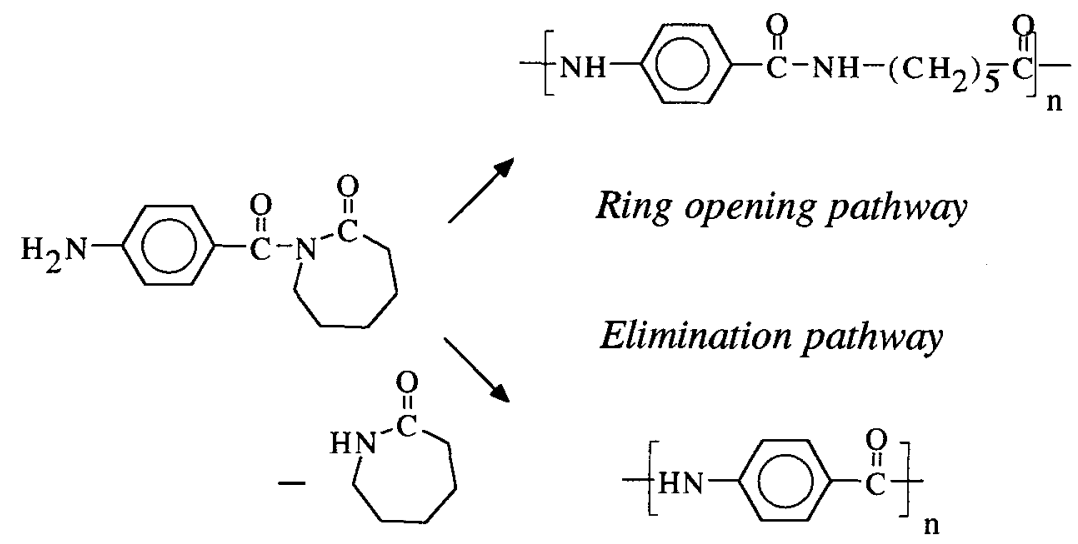

Ring opening pathway

Elimination pathway

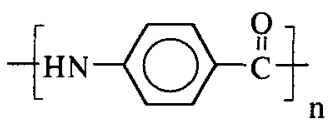

Figure 3. Reaction pathways of the PAC polycondensation via caprolactam elimination and ringopening reaction.

One possible explanation of the high reinforcing efficiency of PAC-based whiskers is the excellent interfacial adhesion between microphase-separated oligomers and the polyamide- 6 matrix. When amino endgroups of the polyamide- 6 are capped with phthalic anhydride, the PAC-based micorparticles decrease the tensile strength of the polyamide- 6 matrix. In the presence of the amine endgroups, the $\mathrm{N}$-acyl-caprolactam functional groups at the particle surface react with amines to form amide coupling groups. This indicates that PAC-based whiskers dispersed in a polymer matrix do not correspond to typical composites but are more similar to microphase separated blockcopolymers of flexible and rigid rod polymers.

The major advantage of the in-situ formation of such anisotropic multiphase polymer is related to processing. While dispersion of short fibers and processing of block copolymers is associated with high melt viscosities, causing processing problems, the in-situ whisker formation involves melting low molecular weight PAC which first reduces melt viscosities and then builds up melt viscosity during processing. Such PAC-based poyamide microcomposites represent a new route to polymer blends using few percent of PAC additives during processing to modify the stiff- 
ness/strength/toughness property balance of polyamide-6.

\section{ELASTOMERIC POLYURETHANE MICROCOMPOSITES}

This concept of in-situ microcomposite formation is also applicable to polyurethane elastomers. When PAC is injected into a polyetherpolyol melt at $200^{\circ} \mathrm{C}$ stable anisotropic polymer polyol dispersions containing poly(p-phenylene benzamide) whiskers dispersed in the polyol are obtained (11). In contrast to the corresponding polyamide-6 dispersions, however, at PAC concentration < 10 wt. $\%$ in diol-terminated poly(oxytetramethylene) with $M_{n}=2000 \mathrm{~g} / \mathrm{mol}$, referred to as PTHF, no whiskers are formed. Preferably, whisker dispersions are produced at $20 \mathrm{wt} . \mathrm{\%}$ PAC content and diluted with additional PTHF to produce polymer polyols with lower solids content. This behavior results from the high endgroup concentration of the low molecular weight PTHF when compared to the high molecular weight polyamide-6. Shown in Figure 4 is the additional side reaction which consumes PAC, eliminates caprolactam and produces aminobenzoate-terminated PTHF via esterification. At high $\mathrm{OH}$ endgroup/PAC molar ratios which correspond to low PAC content, the esterification reaction dominates and prevents PAC-polycondensation. This has been demonstrated by amine- and hydroxy endgroup analyses during PAC in-situ polymerization. As a consequence, PAC concentrations $>10$ wt. $\%$ are required to achieve whisker formation in PTHF melts. Similar to the reaction pathways displayed in Figure 3 , the polymerization temperature is important to control the poly(p-phenylenebenzamide) formation and to prevent incorporation of 6-aminocaproic units. At $200^{\circ} \mathrm{C}$ the dispersed microparticles exclusively consist of highly crystalline poly(p-phenylenebenzamide).<smiles>Nc1ccc(C(=O)N2CCCCCC2=O)cc1</smiles><smiles>OCCCCCCCO</smiles><smiles>CC(O)CCCOC(=O)c1ccc(N)cc1</smiles>

Figure 4. Esterification of PTHF with PAC.

When cured with 4,4'-diisocyanato-diphenyl-methane at $\mathrm{NCO} / \mathrm{OH}$ molar ratios $>1$, slightly crosslinked polyurethanes are formed which exhibit markedly higher strength and modulus without sacrificing high elongation at break. As apparent from Figure 5, such aniostropic polyaramide/polyol dispersions give higher modulus and strength combined with high elongation at break when compared to conventional isotropic fillers, isotropic polyacrylonitrile (PAN)/PTHF dispersions and aminobenzoate-terminated PTHF. 


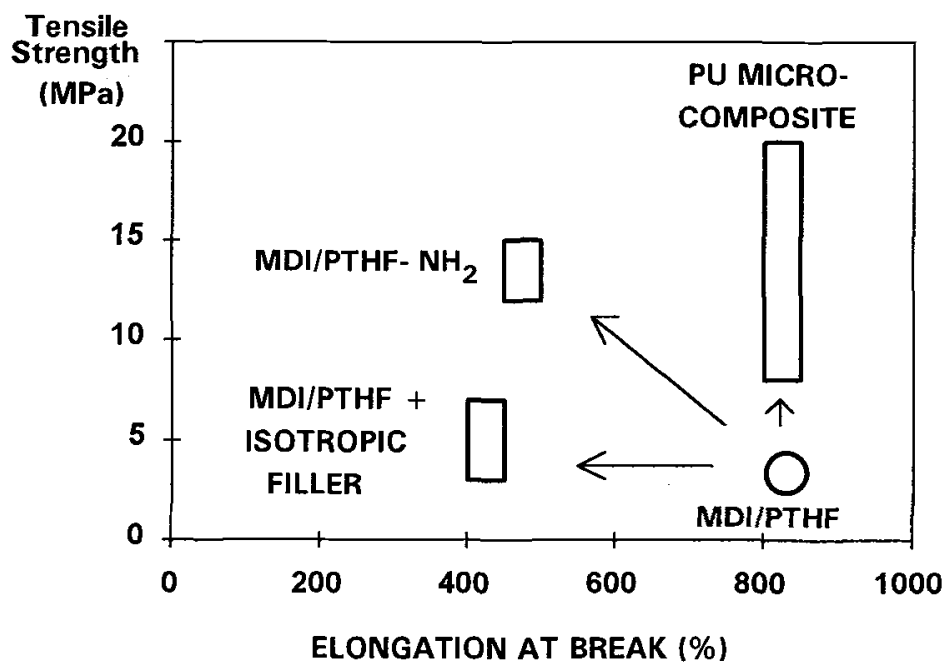

Figure 5. Comparison of strength and ultimate elongation for polyurethane microcomposites compared to polyurethanes reinforced with isotropic fillers (glass beads, PAN-dispersions) and aminobenzoate terminated PTHF (each area refers to 5 - 10 vol.-\% dispersed phase).

In conclusion, the in-situ dispersion polymerization of $\mathrm{N}$-(p-aminobenzoyl)-caprolactam represents a versatile synthetic route to diversify polymer properties during melt processing and to enhance stiffness and strength without sacrificing toughness.

\section{REFERENCES}

(1) G. Slayter, "Two Phase Materials", Sci. Am. 206, 124 (1962).

(2) J.C. Halpin, J. Composite Mater. 3, 732 (1969).

(3) P.J. Flory, Adv. Polym. Sci. 56, 1-36 (1984).

(4) M. Takayanagi, T. Ogata, M. Morikawa, T. Kai, Macromol. Sci.,Phys, B17(4), 591 (1980).

(5) N. Ogata, K. Sanui, H. Itaya, Polymer Journal 22(2), 85 (1990).

(6) G.M. Lenke, D.R. Wiff, Eur. Pat. Appl. 408,166 A2 (1990).

(7) Y. Yamashita, Y. Kato, S. Endo, K. Kimura, Makromol. Chem., Rapid Commun. 9, 687 (1988).

(8) H.R. Kricheldorf, G. Schwarz, F. Ruhser, Macromolecules 24, 3485 (1991).

(9) C. Taesler, J. Petermann, H.R. Kricheldorf, G. Schwarz, Makromol. Chem. 192, 2255 (1991).

(10) L.J. Mathias, D.R. Moore, C.S. Smith, J.Polym.Sci., Part A:Polym.Chem.Ed., 25, 2699-2709 (1987).

(11) J. Rösch, R. Mülhaupt, Am.Chem.Soc., Polym. Chem. Div., Polym. Prepr. 33(1), 370 (1992).

(12) S. Demharter, J. Rösch, R. Mülhaupt, Polym. Bull. (Berlin), in press. 